\section{Utilização de sucedâneos de leite no aleitamento de caprinos mestiços desmamados precocemente}

\author{
Utilization of milk replacers in the rearing of early weaned goats
}

\author{
Jacilene Maria da Cunha CASTRO'; Oziel BIZUT'TI '; \\ Carlos de Sonsa LUCCI "; Laércio MELOTTI ${ }^{2}$
}

\author{
CORRESPONDENCE TO: \\ Carlos de Sousa LuCCi \\ Departamento de Criação de \\ Ruminantes e Alimentaçāo Animal \\ Faculdade de Medicina Veterinária e \\ Zootecnia da USP \\ Av. Duque de Caxias None, 225 \\ Caixa Postal 23 \\ 13630-970 - Pirassununga - SP - Brasil \\ 1 - Universidade Federal da \\ Paraiba - PB \\ 2 - Faculdade de Medicina \\ Veterinária e Zootecnia da USP - SP
}

\title{
RESUMO
}

Foram utilizados 19 cabritos machos e fêmeas, mestiços, com idade de 4 dias e peso médio de $3,09 \mathrm{~kg}$, com o objetivo de avaliar a utilização de sucedâneos de leite sobre o desenvolvimento ponderal de animais desmamados precocemente. O delineamento experimental utilizado foi o inteiramente casualizado, em arranjo fatorial (3x2) em que os tratamentos foram: leite de cabra (T1), sucedâneo com proteínas lácteas (T2), e sucedâneo com proteínas de soja (T3), aplicados a machos e fêmeas. Em todos os tratamentos os animais recebiam mistura de concentrados com $14,0 \%$ de proteína bruta e feno de coast-cross. O consumo de leite e sucedâneos foi restrito a 1,0 litro/animal/dia. Os ganhos diários de peso em T1 $(130 \mathrm{~g})$ foram significativamente maiores $(p<0,01)$ que nos demais tratamentos: T2 (55 g) e T3 $(60 \mathrm{~g})$. Os cabritos foram desmamados aos 56 dias de idade, com pesos médios de 9,51; 6,61 e 6,30 kg (respectivamente para T1, T2 e T3). O presente trabalho mostrou que o emprego de sucedâneos com leite de vaca e com proteína de soja é inferior ao leite de cabra, dentro de um sistema de aleitamento artificial.

UNITERMOS: Substitutos do leite; Desmame; Caprinos.

\section{INTRODUÇÃO E REVISÃO DE LITERATURA}

$\mathrm{M}$ owlem 22 (1979); Havrevoll ${ }^{8}$ (1982); Sanches ${ }^{29}$ (1982); Mouchrek et al.19.20.21 (1987) e Souza ot al.36) (1987) salientam as vantagens do aleitamento artilícial com sucedâneos do leite. Do ponto de vista econômico, Agraz $^{2}$ (1982) encontrou melhores resultados para o aleitamento artificial, contudo, Mattos; Rodrigues ${ }^{13}$ (1982) afirmaram que este sistema exige maior investimento em equipamentos, pessoal mais treinado, nível de higiene mais elevado, além de animais selecionados.

Louca et al. $10(1965)$ verificaram que o crescimento dos cabritos era mais prejudicado quando o peso ao desmame era menor, e Bellaver; Salaive ${ }^{4}(1980)$ recomendam a idade mínima para o desmame aos 60 dias, com média de $8.5 \mathrm{~kg}$ de peso vivo; Sanches29 (1982) estabeleceu que para se proceder ao desaleilamento os animais devem atingir 2,5 vezes seu peso alo nascer, dado esse confirmado também por Morand-Fehr et al. ${ }^{15}$ (1982), sendo o peso nunca inferior at $10 \mathrm{~kg}$ e o consumo de concentrados da ordem de $125 \mathrm{~g} / \mathrm{ani}-$ mal/dia. Owen; Paiva 25 (1982) forneceram sucedâneos para cordeiros, encontrando taxas de crescimento, com desmame às 8 semanas, de $233 \mathrm{~g} /$ dia para o aleitamento à vontade, e $197 \mathrm{~g} / \mathrm{dia}$ para o restrito. Arora et al. ${ }^{3}$ (1982), analisando o crescimento de cabritos, alimentados com leite de cabra e um sucedâneo para bezerros, não verificaram diferenças significativas nas taxas de crescimento, obtendo ganhos de peso médios diários de $74 \mathrm{~g}$ e $68 \mathrm{~g}$ e relações alimento/ganho de 1,63 e 2,38 respectivamente. Maiorana et al. $"$ (1984) verificaram que cabritos alimentados com sucedâneos com proteínas lácteas "ad libitum" obtiveram melhores ganhos de peso, bem como algumas medidas de carcaça, quando comparados àqueles criados tradicionalmente. Saini et al.28 (1986) encontraram ganhos de peso da ordem de $76 \mathrm{~g} / \mathrm{dia}$ para cabritos alimentados com sucedâneo e $79 \mathrm{~g} /$ dia para os que recebiam leite integral; Marques; Godoy'2 (1982) obtiveram peso médio de $10,3 \mathrm{~kg}$ ao desmame com 60 dias de idade, ganho de peso médio de $125 \mathrm{~g}$ e índice de conversão alimentar de 1:I, usando leite em pó; Agraz² (1982) encontrou ganhos de peso médio de $146 \mathrm{~g} /$ dia para animais criados em regime tradicional, e $157 \mathrm{~g} /$ dia para aqueles criados artificialmente. Morand-Fehrit $(1981)$ encontraram taxas de crescimento semelhantes quando usaram leite de cabra ou sucedâneo em caprinos; Mouchrek et cl. ${ }^{18 .}$ 20) $(1989,1987)$ utilizaram leite de vaca no aleitamento de cabritos, não encontrando diferenças significalivas nos desempenhos.

Estudando a proteína da soja em sucedâneos para bezerros, Mattos; Rodrigues ${ }^{1.3}$ (1982) e Khorasani et al. ${ }^{9}(1989)$ veri- 
CASTRO, J.M.C.: BIZUTTI. O.: LUCCI, C.S.; MELOTTI, L. Utilização de sucedâneos de leite no aleitamento de caprinos mestiçns desmamados precocemente. Braz. J. vet. Res. anim. Sci. São Piulo, v.33. n.3. p.160)-16.1. 1906.

ficaram que depressores do crescimento prejudicam a digestibilidade da proteína e diminuem a formação de coágulos no abomaso. Tanabe; Kameoka ${ }^{32}$ (1977) mostraram que a substituição da proteína do leite pela soja reduz a taxa de crescimento em $27 \%$ devido à diminuição na digestibilidade. Já Prado et al.26 (1989) utilizaram um sucedâneo contendo $24,3 \%$ de proteína texturizada de soja (PTS) e constataram ser possível a substituição total de leite de cabra por esse produto. Mouchrek; Moulin ${ }^{19}$ (1987) ulilizaram leite de soja no aleitamento de caprinos na proporção de $25 \%$ a $50 \%$ da mistura, e obtiveram pesos ao desmame, próximos de $10 \mathrm{~kg}$; consumo de concentrados de 75 g/dia de peso médios diários de $137 \mathrm{~g}$ para leite de cabra e 125,8 g para "leite de soja". Mouchrek et al.16 (1989) utilizaram com sucesso "leite de soja" compondo o mínimo de $40 \%$ e o máximo de $66,7 \%$ da mistura láctea.

Segundo Abrams el al.' ( 1985 ), a composição em MS do sucedâneo de leite influi no desempenho dos animais. Morand-Felir et al. ${ }^{15}$ (1982) obliveram taxas de crescimento compensadoras quando os sucedâneos apresentavam de 10 a $25 \%$ a mais de matéria seca do que o leite integral; Ramagosa Vila27 (s.d.) verificou tendência de maior consumo quando o nível de matéria seca era superior a $10 \%$; Mowlem23 (1981) observou taxas melhores de crescimento quando a concentração do leite era de $18 \%$, a mesma empregada por Havrevoll ${ }^{\times}$(1982) e Marques; Godoy'2 (1982) usaram leite em pó com $13,5 \%$ PB e $20 \%$ de gordura, numa concentração de 15\%; Mowlem ${ }^{24}$ (1982) testou níveis de $24 \%$ PB, $12 \%$ de gordura e 14\% de matéria seca. Owen; Paiva ${ }^{23}$ (1982) compararam sucedâneos de leite desnatado com $20 \%$ de gordura e $18 \%$ de sólidos. Esses mesmos autores estudaram sucedâneos com níveis variáveis de matéria seca $(17 \%, 13,5 \%$ e $10 \%)$ e verificaram que à medida que aumentava a diluição, diminuía o consumo por parte dos animais.

\section{MATERIAL E MÉTODO}

O experimento foi conduzido no município de Analândia - SP, distante $15 \mathrm{~km}$ das dependências da Faculdade de Medicina Veterinária e Zootecnia da USP, em Pirassununga - SP. As instalações eram compostas de 6 baias coletivas cobertas, de ripado suspenso, com cochos externos para volumoso e concentrados e bebedouro. Anexa às baias havia uma área descoberta que servia de piquete para exercício e solário. Foram utilizados 19 cabritos, machos e fêmeas mestiços, recém-nascidos, com idade de 4 dias e peso médio de $3.09 \mathrm{~kg}$. Após o nascimento, os animais permaneceram com as mães por um período de 4 dias para mamarem o colostro. Em seguida, foram distribuídos para os tratamentos, onde permaneceram até o desmame, aos 56 dias de idade. Os tratamentos foram distribuídos em um arranjo fatorial $3 \times 2$ (tipos de leite $x$ sexo), sendo os tipos de leite: T1 - Leite de cabra; T2 - Sucedâneo de leite com proteínas lácteas e T3 - Sucedâneo de leite com proteínas de soja, em delineamento inteiramente casualizado, com número diferente de repetições por tratamentos. As dilerenças entre médias de tratamento foram comparadas pelo teste de Tuckey (Gomes?, 1985).

Os sucedâneos eram oferecidos aos animais na concentração de $10 \%$, utilizando-se mamadeiras individuais, sendo o leite fornecido à temperatura de 38 a $39^{\circ} \mathrm{C}$, sempre nos mesmos horários, às $6: 30 \mathrm{~h}$ e às $16: 30 \mathrm{~h}$. O consumo de leite era restrito a $1,0 \mathrm{~kg}$ (até 42 dias de idade), $0,75 \mathrm{~kg}, 0,50 \mathrm{~kg}$ e 0,251 kg respectivamente para 42-49 dias, 50-52 dias e 5356 dias. A partir do oitavo dia de idade, lodos os animais recebiam uma mistura concentrada peletizada, com $14,8 \%$ de proteína bruta, e feno de coast-cross (Cynodon dactylon. Pers) à vontade, além de mistura de sal mineralizado. Na Tab. I encontra-se a composição química dos sucedâneos de leite utilizados no presente trabalho.

Os cabritos foram pesados ao nascer e a cada 7 dias, até o desmame, sempre no mesmo horário, antes da primeira refeição láctea. Diariamente eram registrados os consumos individuais, do leite e dos sucedâneos, durante todo o período experimental. A partir da terceira semana, as quantidades diárias de concentrados e feno oferecidas e recusadas foram registradas nas baias coletivas.

\section{RESULTADOS E DISCUSSAOO}

Na Tab. 2 constam as médias e coeficientes de variação dos pesos ao nascer, aos 7, 14, 21, 28, 35, 42, 49 e 56 dias de idade, por tratamento.

Foram observadas diferenças significativas $(\mathrm{P}<0,() \mid)$ nos pesos aos 56 dias de idade, entre sexos, e para tratamentos nos machos, tendo o tratamento $\mathrm{TI}$, neste sexo, ( $\mathrm{T} / \mathrm{m}$ ) apresentado média superior ao tratamento T2, (T2m) e a T3, (T3m), ou seja, os sucedâneos foram inferiores, quanto ao desempenho, em relação ao aleitamento com leite de cabra. Nenhuma diferença significativa foi observada entre tratamentos nas fêmeas.

Aos 56 dias de vida, os animais no tratamento $\mathrm{TI}$ alcançaram pesos próximos aos sugeridos por Marques; Godoyl2 (1982); Sanches29) (1982) e Mouchrek ef al. ${ }^{16}$ (1989). Entretanto, os cabritos dos tratamentos T2 e T3 apresentaram pesos muito inferiores aos registrados por Marques; Godoy'2 (1982) e Mouchrek ef al.'6 (1989).

Analisando o ganho de peso dos animais no período entre o nascimento e os 21 dias de idade, verificou-se que o tratamento $\mathrm{T} 1$ diferiu significativamente $(\mathrm{P}<0,05)$ de T2 e T3, tanto entre machos como entre fêmeas, mostrando a superiori- 


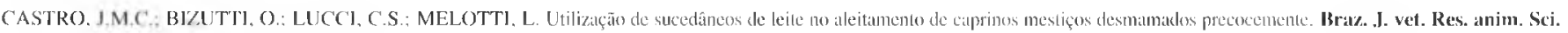
São Pitulo, v.33, 11.3, p.160-164, 1996

Tabela 1

Composição química dos sucedâneos de leite, dos concentrados e do feno, em porcentagem, utilizados durante o periodo experimental. Analândia - SP, 1988.

\begin{tabular}{lrrrr}
\hline Nutrientes & Concentrado & Feno & $\begin{array}{c}\text { Concentrados com proteína } \\
\text { láctea }\end{array}$ & \begin{tabular}{c} 
de soja \\
\hline MS (\%)
\end{tabular} \\
PB (\%) & 14,0 & 88,65 & 92,0 & 92,00 \\
FB (\%) & 7,04 & 3,30 & 21,0 & 25,50 \\
EE (\%) & 1,76 & 1,72 & 1,50 & 5,00 \\
ENN (\%) & 70,08 & 49,72 & 15,00 & 9,00 \\
MM (\%) & 7,04 & 4,82 & 80 & 42,00 \\
Ca (\%) & -- & 0,49 & 2,0 & 10,50 \\
P(\%) & -- & 0,059 & 0,00 & 1,80 \\
\hline
\end{tabular}

neos foram empregados em concentração de $10 \%$, igual à sugerida por Ramagosa Vila $^{27}$ (s.d.), porém inferior às empregadas por Mowlen 2.3 (1981); Havrevoll (1982); Morand-Fehr et al. ${ }^{5}$ (1982). Mowlen24 (1982); Owen; Paiva25 (1982) observaram melhores taxas de crescimento cuanclo o sucedâneo apresentava de 18 a $20 \%$ de matéria seca. MorandFehr et al. ${ }^{15}$ (1982) obtiveram taxas de crescimento compensadoras quando o sucedâneo apresentava de 10 a $25 \%$ a mais de matéria seca do que o leite integral. Dessa forma, os baixos ganhos de peso observados nos tratamentos T2 e T3

dade do leite de cabra em relação aos sucedâneos, nesse período. Os ganhos totais de peso, do nascimento aos 56 dias, mostraram diferenças significativas entre tratamentos $(\mathrm{P}<0,01)$; para os machos como para as fêmeas, o tratamento $\mathrm{T} 1$ superou significativamente os tratamentos T2 e T3.

Os resultados obtidos discordam de Havrevoll ${ }^{8}$ (1982); Mowlem $^{24}$ (1982) e Maiorana et al. ${ }^{11}$ (1984), que encontraram melhores ganhos de peso com a utilização de sucedâneos com proteínas lácteas do que com leite de cabra. Morand-Fehr et al. ${ }^{15}$ (1982) não encontraram diferenças nos ganhos, quando usaram leite de cabra e um sucedâneo. No presente caso, o sucedâneo com proteínas de soja não diferiu do sucedâneo com proteínas lácteas, em termos de ganhos de peso, embora a utilização de proteína de soja em sucedâneo de leite tenha sido muito criticada (Gardner et al. ${ }^{6}$, 1982; Mattos; Rodrigues ${ }^{13}, 1982$; Khorasani et al. ${ }^{4}, 1989$ ). No entanto, Mouchrek et al.20 (1987) obtiveram peso ao desmame próximo de $10 \mathrm{~kg}$ empregando "leite de soja" no aleitamento de caprinos, superando os valores registrados no T3 do presente experimento. No caso presente, os sucedâ- podem ter ocorrido devido à concentração dos sucedâneos ser de apenas $10 \%$ de sólidos.

O nível de gordura do tratamento sucedâneo com leite de vaca (T2) foi de $15 \%$, superior ao utilizado por Morand-Fehr et al. ${ }^{15}$ (1982) e inferior aos empregados por Marques; Godoy 12 (1982) e Owen; Paiva ${ }^{25}$ (1982), e o do tratamento sucedâneo com proteína de soja (T3) apresentava $9,0 \%$ de gordura. Apesar do tratamento sucedâneo com leite de vaca (T2) ter apresentado maior nível de gordura do que o sucedâneo com proteínas de soja (T3) os ganhos de peso nesses tratamentos, fornecidos na mesma concentração da matéria seca, não diferiram estatisticamente. Mattos: Rodrigues ${ }^{3}$ (1982) relataram que a baixa qualidade e a incorporação inadequada da gordura diminui sua digestibilidade, o que implicaria desempenho inferior.

O nível de proteínas dos sucedâneos T2 e T3 foi de $21 \%$ e 25.5\%, respectivamente, próximos aos sugeridos por Marques; Godoy'2 (1982) e Mowlen²4 (1982).

Com relação às taxas de ganhos de peso com o leite de cabra, de $130 \mathrm{~g} / \mathrm{animal} / \mathrm{dia}$, ultrapassaram os resultados de

Tabela 2

Médias e coeficientes de variação dos pesos ao nascer, e dos 7 aos 56 dias de idade (machos e fêmeas) em kg, por tratamento. Analândia - SP, 1988.

\begin{tabular}{|c|c|c|c|c|c|c|c|}
\hline \multirow[b]{2}{*}{ Idade (dias) } & \multicolumn{7}{|c|}{ TRATAMENTOS } \\
\hline & TIM & $\mathrm{T} 1 \mathrm{~F}$ & $\mathrm{~T} 2 \mathrm{M}$ & $\mathrm{T} 2 \mathrm{~F}$ & T3M & T3F & C.V. $(\%)$ \\
\hline Peso do nascer & 2,99 & 2,47 & 2,80 & 3.56 & 2,81 & 3,38 & 17.01 \\
\hline Peso aos 7 dias & 3,17 & 2,85 & 3,12 & 3,66 & 3,05 & 3,49 & 14,53 \\
\hline Peso dos 14 dias & 4,04 & 3,67 & 3,30 & 3.79 & 3,25 & 3,70 & 11,40 \\
\hline Peso aos 21 dias & 5,07 & 4,38 & 3,67 & 4,06 & 3,37 & 3,52 & 17,54 \\
\hline Peso aos 28 dias & 6,05 & 5,23 & 3,70 & 4,24 & 3,85 & 3,95 & 20,73 \\
\hline Peso aos 35 dias & 7,02 & 5,71 & 4,10 & 4,70 & 4,10 & 4,46 & 22,26 \\
\hline Peso aos 42 dias & 8,17 & 6,46 & 4,42 & 4.99 & 4,50 & 5,24 & 25,17 \\
\hline Peso aos 49 dias & 9,25 & 6,66 & 5,0 & 5.10 & 5,20 & 5,75 & 26,90 \\
\hline Peso aos 56 dias & 10,85 & 7.72 & 5,35 & 6,61 & 6,00 & 6.44 & 27,53 \\
\hline
\end{tabular}


Arora et al. ${ }^{3}$ (1982) e Saini et al.28 (1986), porém, sendo inferiores aos encontrados por Mouchrek et al. ${ }^{20}$ (1987). Já quanto ao sucedâneo com proteínas lácteas, os ganhos de peso foram $55 \mathrm{~g} / \mathrm{animal} / \mathrm{dia}$, muito inferiores aos observados por Arora et al.3 (1982); Marques; Godoy'2 (1982) e Owen; Paiva ${ }^{25}$ (1982). Agraz ${ }^{2}$ (1982) encontrou ganhos de peso diários de $157 \mathrm{~g}$ em aleitamento artificial, valor consideravelmente superior alos observados no presente experimento. Os ganhos diários de peso no tratamento T3, com soja, foram de $60 \mathrm{~g} / \mathrm{animal} / \mathrm{dia}$ inferiores aos dados de Mouchrek et al. ${ }^{20}$ (1987), que empregaram também sucedâneo contendo proteína de soja; Prado et al.26 (1989) afirmaram ser possível a substituição do leite de cabra pelo "leite de soja". Contudo, Tanabe; Kameoka ${ }^{32}$ (1977) mostraram que a utilização de soja reduz as taxas de crescimento de cabritos pré-ruminantes em $27 \%$, devido ao decréscimo na digestibilidade da proteína, concordando com Mattos; Rodrigues ${ }^{13}$ (1982) e Khorasani et al. ${ }^{9}$ ( 1989).

O consumo de leite e sucedâneos foi limitado no máximo a 1,0 litro/animal/dia, de acordo com Souza et al. ${ }^{30,31}$ ( 1987 , 1983) e Mouchrek et al. ${ }^{17}$ (1989). Observou-se ainda que a ingestão de alimento líquido por tratamento foi semelhante.

Os ganhos de peso maiores nos animais alimentados com leite de cabra, consumindo a mesma quantidade de leite que aqueles que recebiam sucedâneos, discordaram dos de Bhattacharya $^{5}(1980)$, que encontrou melhores taxas de crescimento somente quando o consumo de leite era mais alto.

Os consumos de concentrados nos três tratamentos estão superiores aos observados por Morand-Fehrl4 (1981) e Mouchrek et al.20 (1987). Apenas o tratamento T2 apresentou valores abaixo do estabelecido por Sanches ${ }^{29}$ (1982). Foi observado que o consumo de concentrados e feno pelos animais alimentados com sucedâneos foi menor que o dos que recebiam leite de cabra. Isto por ter ocorrido devido aos menores ganhos de peso alcançados com os sucedâneos, e consequientemente menor apetite.

Os animais alimentados com leite de cabra apresentaram melhor conversão alimentar do que os que receberam sucedâneos de leite. Os resultados encontrados, 1,66, 3,10 e $3,20 \mathrm{~kg}$ de $\mathrm{MS}$ ingerida/kg de ganho de peso vivo, respectivamente para os tratamentos T1, T2 e T3, foram inferiores aos registrados por Arora et al. ${ }^{3}$ (1982) e Marques; Godoyl2 ( 1982). Porém, Maiorana et al." (1984) encontraram índice de 3,37 ulilizando um sucedâneo com proteínas lácteas.

O desaleitamento ocorreu aos 56 dias de idade, estando os animais com pesos médios $(\mathrm{kg})$ de $9,51,6,61$ e 6,30 e apresentando consumos médios de concentrados de 176,45, 116,14 e 141,57 g/animal/dia respectivamente, para os tralamentos T1, T2 e T3. Observou-se que os animais no tratamento $\mathrm{T} 1$ foram desmamados com $9,51 \mathrm{~kg}$ de peso, correspondente a 3,4 vezes o peso ao nascer e consumindo $176,45 \mathrm{~g}$ de concentrado. Morand-Fehr et al. ${ }^{15}$ (1982) e Sanches ${ }^{29}$ (1982) sugerem desmame com peso mínimo de $10 \mathrm{~kg}$, e Bellaver; Salaive $^{4}(1980)$, peso de $8,5 \mathrm{~kg}$. Os tratamentos T2 e T3 não atenderam a esses requisitos.

\section{CONCLUSÕES}

Nas condições particulares do presente experimento, as seguintes conclusões podem ser enunciadas; para um sistema de aleitamento artificial.

1 - Sucedâneos com proteínas lácteas são inferiores ao emprego do leite de cabra, tendo em vista ganhos de peso do nascimento aos 56 dias de idade.

2- Sucedâneos com "leite de soja" são inferiores ao emprego do leite de cabra, tendo em vista ganhos de peso do nascimento aos 56 dias de idade.

\section{SUMMARY}

Nineteen 4 day-old crossbred kids, with $3.09 \mathrm{~kg}$ average birth-weight, were used to evaluate the effect of milk replacers on the development of early weaned goats. A completely randomized design, with a factorial arrangement $(3 \times 2)$, was used in the treatments: goats milk (T1), milk replacer with cow milk (T2) and milk replacer with soybean protein (T3), all applied in males and females. A concentrata mixture with 14.0 crude protein and grass hay was used in all treatments. Liquid feed consumption was restricted to a maximum of $1.0 \mathrm{~kg} /$ day. Treatment T1 presented significantly higher $(\mathrm{P}<0.01)$ daily weight gain $(130 \mathrm{~g})$ than T2 $(55 \mathrm{~g})$ and T3 $(60 \mathrm{~g})$. Liquid feed consumption was similar for all treatments, and final weights were $9.5 \mathrm{~kg} ; 6.6 \mathrm{~kg}$ and $6.3 \mathrm{~kg}$ (T1, T2 and T3 respectively). Milk replacer was concluded as inferior to goat milk in artificial rearing.

UNITERMS: Weaning; Goats; Milk substitutes. 


\section{REFERENCIAS BIBLIOGRÁFICAS}

I- ABRAMS; E.: GUITHRIE, P.; IIARRIS, B. Eflect of dry miller intike from whole goat milk and calf milk replacer on performance of Nubian goat kids. Journal of Dairy Science, v.68, p.1748-51, 1985

2- AGRAZ A. A. Zoo-cconomics analysis of artificial and nallural of kids. In: INTERNATIONAL, CONFERENCE ON GOAT PRODUCTION AND DISEASF:. 3.. Tucson. 1982. Proceedings. p.544.

3-ARORA, S.P.: CIIOPRA, R.C : ATREJA, P.P. Relative perlomance of kids fed milk and milk replacer on growth rate. Indian Journal of Dairy Science, v.35, p.6-8, 1982.

4-BELLAVER, C.: SALAIVE. A. A importância do desmame dos cordeiros e cabritos. (omunicado T'́ćnico: Centro Nacional de Pesquisa de Caprinos, 11,2, p. 1-4, 1980.

5-BHATTACHARYA. A.N. Research on goat nutrition and management in Mediterranean Middle East and Adjacent Arab Countries. Journal of Dairy Science, v.63, p. 1681-700, 1980 .

6.GARDNER, R.W.: MARTINS, D.L.: WEBER. D.J. Allergenicily of soybeim milk replacers fed lo calves. Journal of Dairy Science, v.61, p.222, 1982 (Abstract).

7-GOMLS. Fi.'. Curso de estatística experimental. 11 .ed. Piracicabal, NobelESALQ, 1985.

8-HAVREVOLI, O. Milk and milk replacers as feeds for rearin dairy foats. In: INTER NATIONAL CONFERENCE ON GOAT PRODUCTION AND IDISEASE, 3.; Tucson, 1982. Proceedings, p.492.

9-KHORASANI, G.R.: OZIMEK, L.: SAVER. W.C.: KENNELY. J.J. Substitution of milk protein with isolated soy protein in calf milk replacers. Journal of Animal Science, v.67, p. 1634-41, 1989.

I0-LOUCA. A.: MAVROGENIS. A.: LAWL.OR, M.J. The effect of early weaning on the lactation of Damascus goat and the growth rate of the kids. Animal Production, v.20, p.213-8, 1965.

II-MAIORANA, M.; RUBINO, R.; PIZZIL.L.O. M. Lallettamento antificiale nell allevamento caprino. Annali dell Istituto Sperimentali di Zootecnia. v.2, p.117-36. 1984.

12-MARQUES. F.: GODOY, A. Arificial rearing im Murciana Granadina Kids. In: INTERNATIONAL, CONFERENCE ON GOAT PROIJUCTION AND DISEASE, 3., Tucson, 1982. Proceedings, p.543.

1.3-MAT"TOS, L.L.; RODRIGUES, A.A. Desalcitamento precoce de bezerros. Informe $\Lambda$ gropecuário. v.8, n.95, p.3-7. 1982.

14-MORAND-FEHR. P. Growh. In: GALL. C. Goat production. L.ondon. Acardemic Press, $1981 . \mathrm{p} .52-83$.

15-MORANID-FEIIR, P.: IIERVIEU, J.: BAS. P.: SAUVANT, D. Ficeding of young goats. In: INTERNATIONAL CONFERENCE ON GOA'T PRODUCTION AND DISEASF., 3., Tucson, 1982. Proceedings, p. $)(0-104$.

I6-MOUCHREK, E.; CAPRISTANO, C : MONTEIRO, P.A.; STHELING, R.: 'TANAKA, T': I INHARES, F. Sistemas economicos de aleitamento para caprinos 4: utilização progressiva de leite de soja cm mistura com leite de cabra. In: REUNIÄO ANUAL DA SOCIEDADE BRASIL.EIRA DE: \%OO'TICNIA. 26. Porto Alegre. 1989. Anais. p.432.

17-MOLCHIREK, E.: I.JNHARES, I:: TANAKA. T. Efeito da resiriçĩo no consumo de leite sobre o desenvolvinemto ponderal de caprinos $3 / 4$ de sangue leiteiros. In: REUNIÄO ANUAL. DA SOCIEDADE BRASILEIRA DE \%OO'IICNIA, 26., Porto Alegre, I989. Anais, p.298.

I8-MOUCIIREK. E.: LINHARES, F; TANAKA. T. Desenvolvimento ponderal de caprinos mestiços leiteiros até 56 dias de idade (desaleitamen(o) precoce). In: REUNIÄO ANUAL DA SOCIEDADE BRASILEIRA DE ZOOO'TECNIA. 26.. Porlo Alegre, 1989. Anais. p.433.

19-MOUCHREK, E:: MOULIN, C.IL.S. A importância do binônio frecuiencia $x$ consumo diário no aleitamento artificial e de caprinos. Informe Agropecuário, v. 13, 11.146, p.20-3, 1987

20-MOUC'HREK, E.; MOULIN, C.H.S.; LINHARES, F.; TANAKA, T' Alimentação artificial de caprinos mestiços leiteiros. In: ENCON'TRO ANUAL. SOBRE CAPRINOCULTURA LEITEIRA. 3., Nova Odessa, 1987. Anais. Nova Odessia. Instituto de Zootecnia. 1987. p.15-42.
2I-MOUCHREK, E.: MOULIN. C.H.S.: TANAKA. T. Sislemas cconômicos de alcitamento paral caprinos: uilização do leite de vaca como suededîneo do leite de calbra. Informe Agropecuário. v. 13, 11. 146, p.16-9, 1987.

22-MOWLEM, A. Milk replacer for kid rearng. British Goal Society Yearbook, p.54-7, 1979.

23-MOWLEM, A. Recents advances in kid rearing. British Goat Society Monthly Journal, 11.3, p.41-2, 1981.

24-MOWLEM. A. Rearing dairy goal kids using milk replacer. In: INTERNATIONAL CONIIRENCEON (IOAT PRODUIC"IION AND DISEASE, 3.. Tucsom, 1982. Procecedings, p.491.

25-OWEN, E.: PAIVA, P. Arrilicial rearing of goats kids. In: INTERNATIONAL, CONFERENCE ON (IOAT PROI)LICTION AND DISEASE, 3., Tucison, 1982. Proceedings, p.491.

26-PRADO, I.N.; MARTINS, E.N.; MACEDO, FA.F.; SANTOS, G.T. Efeito da substituição do leite de cabra pelo leite de valca c proténa de soja sobre o descenvolvimento de cabritos pré-ruminantes. In: REUNIÃO) ANUAL DA SOCIEDADE BRASILEIRA DE ZOO'TECNIA, 26. Porto Alegre, 1989. Anais. p. 173.

27-ROMAGOSA VILA, J.A. Manejo de cabras y cabritos en cebo precoz. Madrid, Editora Pons, s.d.

28-SAINI, A.L.; PRAKASH, B.; KIIAN, B.U. lnfluence of sukling period on growth and survivability of kids and economics of rearing. Indlian Journal Animal Production and Management. v.2. 11.4. p.171-4. 1986.

29-SANCHES. L.N. Níveis nutricionatis recomendados parra caprinos em crescimento. Informe Agropecuário. v.8. 17.95, p.46-51. 1982.

30-SOUZA, W.H.; ZOMETA, C.A.; BARROS, N.N. Inluência do sistema de alimentação no desmame precoce de cabritos de exploração leiteira. In: PRODUÇÃO TÉCNICO-CIEN'TífICA. 1980-1986. João Pessoa, 1987. Resumos. Joño Pessoa, EMEPA. p.104.

31-SOUZA. W.H.: ZOMETA. C.A.: BARROS. N.N.: ROBB. T.W.: JOHNSON, W.L. Idade e peso no inicio da ruminação em cabritos das raças AngloNubiana e Parda Alcmã. In: REUNIÄO ANUAL. DA SOCIEDADE BRASILEIRA DE ZOOTEC NIA, 22.. Pelolas, I983. Anais, p. 144.

32-TANABE, S. KAMEOKA. K. Growth and nutrient utilization by kid. led milk replacer containing isolated soybean protein as the sole source of protein. Japanese Journal of the Zoolechnical Science. v. 48, n. 7, p. $361-70.1977$.
Recebido para publicação: 01/07/94 Aprovado para publicação: 08/11/95 